\title{
Biochemical, Endocrine and Genetic Impairments in Response to Agrochemicals Intoxication in Common Carp (Cyprinus carpio)
}

\author{
Sanna $^{1}$, Shehzad Ghayyur ${ }^{1}$, Sadia Tabassum ${ }^{1}$, Shumaila Noreen ${ }^{1}$, Sajid Mahmood ${ }^{1}$, Mujadad Ur Rehman ${ }^{2}$, Bashir \\ Ahmad $^{3}$, Muhammad Kabir ${ }^{4}$, Muhammad Sajid ${ }^{5}$ and Muhammad Fiaz Khan ${ }^{*}$ \\ ${ }^{1}$ Department of Zoology, Hazara University, Mansehra, Pakistan \\ ${ }^{2}$ Department of Microbiology, Abbottabad University of Science and Technology, Abbottabad, Pakistan \\ ${ }^{3}$ Department of Zoology, University of Haripur, Haripur, Pakistan \\ ${ }^{4}$ Department of Forestry and Wildlife Management University of Haripur, Haripur, Pakistan \\ ${ }^{5}$ Department of Biochemistry, Hazara University, Mansehra, Pakistan \\ *For correspondence: fiazkhanhu333@gmail.com \\ Received 09 January 2021; Accepted 12 March 2021; Published 10 May 2021
}

\begin{abstract}
Worldwide extensive use of agrochemicals in agricultural production poses potential ecotoxicological effects and disturbs aquatic biota, more specially fish. This study aims to evaluate comparative effects of selected agrochemicals such as profenofos, endosulfan and deltamethrin on biochemical, endocrine and genetic profiles of the common carp (Cyprinus carpio L.). Forty healthy carp $(50 \pm 7.45 \mathrm{~g}$ and $15 \pm 5.86 \mathrm{~cm})$ were selected randomly and equally divided into four groups; control group labeled as E0 and three treated groups having 4 ppb of profenofos, deltamethrin and endosulfan, labeled as E1, E2, E3 respectively. Fish were exposed to chemicals for $96 \mathrm{~h}$. Obtained results revealed that, significant changes were observed in biochemical parameters of treated groups in comparison with control group $(P<0.05)$ : glucose, creatinine, serum amylase, alkaline phosphate, sodium and phosphorus levels increased significantly, while a significant $(P<0.05)$ reduction was recorded in serum protein, triglycerides, serum lipase and magnesium levels. Whereas significant increase in TSH and cortisol levels were found, while significant decrease $(P<0.05)$ in T3, T4 and insulin level were observed in experimental groups as compared to control group. Genetic parameters were also affected under the stressors and showed significant increase $(P<$ $0.05)$ in micronuclei frequency in erythrocytes of treated fish compared to the control group. Toxicities of the three agrochemicals were: endosulfan $>$ deltamethrin $>$ profenofos. The obtained results provide solid evidence that unobservant use of such agrochemical causes a pernicious effect on nontarget organisms such as fish. (C) 2021 Friends Science Publishers
\end{abstract}

Keywords: Profenofos; Deltamethrin; Endosulfan; Fish; Health

\section{Introduction}

Agrochemical is a substance or mixture of substances that is use for preventing, abolishing, resisting or mitigating any pest for enhancement in crop yield. Agrochemicals are frequently applied to agricultural commodities in order to fulfill the increasing food demand and for protection of crops from pests, pathogen and weeds (Gupta et al. 2013). Along with beneficial effects these agrochemicals have some disadvantages such as odor and change in taste of water and lethality of non-target organisms in aquatic environment (Sathyamoorthi et al. 2019). Pesticides enter in aquatic environment through runoff from place of application and pose a serious threat to aquatic life (AlOtaibi et al. 2019). Aquatic organisms face significant problems similar to terrestrial species analysis of fish and water samples from different aquatic environments shows $90 \%$ to have one or more than one toxicant (Hussain et al.
2020). On the basis of chemical nature and mode of action agrochemical are categorized into five major categories namely; oraganochlorine, organophosphate, carbamates, pyrethroids and neonicotinoids (Xiao et al. 2017).

Profenofos is broad spectrum organophosphate highly effective for controlling chewing and sucking insects and mites mostly present on cotton plants (Reddy and Rao 2008). Deltamethrin is a synthetic pyrethroid., Natural pyrethrins are from Chrysanthemum cinerariaefolium (Bradberry et al. 2005). It is used to control aphids, white flies, lice, tsetse flies, fleas, ticks, spiders, bees, cockroaches, ants, weevils, beetles and bedbugs (Costa 2015). Endosulfan is an organochlorine is preferred for pests management programs such as mosquitoes and tsetse fly public health control programs (Guo et al. 2008).

As fish are in direct contact with water, they are exposed to the toxic chemical and accumulate raising concern about their biomagnification potential in the food

To cite this paper: Sanna, S Ghayyur, S Tabassum, S Noreen, S Mahmood, MU Rehman, B Ahmad, M Kabir, M Sajid, MF Khan (2021). Biochemical, endocrine and genetic impairments in response to agrochemicals intoxication in common carp (Cyprinus carpio). Intl J Agric Biol 25:1255-1262 
webs (Zhang et al. 2020). Agrochemicals can disturb physiological functions and biochemical processes of organisms, so biochemical and endocrine parameters can be used as a biomarkers of stressor impacts (Isaac et al. 2017). Potential genotoxicity of pesticides are usually first monitored by using the micronucleus assay; a reliable, simple, easily performed bioassay (Talapatra and Banerjee 2007; Hemalatha et al. 2020). Induction of micronuclei in peripheral erythrocytes can be used as a biomarker for ecotoxicology, which can lead to damaging effects like retardation of growth and abnormal development in fish (Caliani et al. 2019). Common carp (Cyprinus carpio L.) is the third most frequently introduced important aquaculture species, and is source of $71.9 \%$ fresh water production, and a well-studied aquatic model organism in ecotoxicology when OECD standard bioassays are used (Rahman 2015). The aim of current study was to evaluate the comparative adverse effects of endosulfan, profenofos and deltamethrin on health status of the common carp during 96-h acute exposure.

\section{Materials and Methods}

\section{Fish collection and acclimatization}

Total one forty widespread freshwater omnivorous fish, Common carp (Cyprinus carpio) $(50 \pm 7.45 \mathrm{~g}$ and $15 \pm 5.86$ $\mathrm{cm})$ were collected from fish farm service road Kamra, Punjab Pakistan and brought to laboratory of Zoology department at Government Postgraduate College Haripur. Fish were allowed to acclimatize to lab condition for ten days prior to experiment, during this time period fish were fed with pelleted fish food and $70 \%$ of water was renewed on alternate days in order to prevent accumulation of toxic substances. The $\mathrm{pH}$ and temperature of laboratory water were maintained at $7.6-7.8$ and $20-23^{\circ} \mathrm{C}$, respectively.

\section{Selected chemicals for exposure}

Mmarketable commercial formulations of profenofos (40 $\mathrm{EC})$, deltamethrin (60 EC) and endosulfan (37 EC) were selected for the study and purchased from local agrochemicals market of Peshawar Khyber Pakhtunkhwa, Pakistan.

\section{Experimental setup}

To investigate the possible toxic effect of Profenofos, Deltamethrin and Endosulfan, test solution of $4 \mathrm{ppb}$ was prepared for each chemical from their commercial formulation. On the basis of fish mortality response and agrochemical concentration, the LC50 of profenofos, deltamethrin and endosulfan by Probit analysis (Finney 1980) was found to be $8.34 \mu \mathrm{g} / \mathrm{L}, 11.92 \mu \mathrm{g} / \mathrm{L}$ and 9.58 respectively for $96 \mathrm{~h}$. Four glass aquaria of $60 \mathrm{~L}$ capacity were filled with $40 \mathrm{~L}$ of water and labeled as E0, E1, E2 and E3. E0 was control group having no chemical while E1 experiment one, E2 experiment two, E3 experiment three.
Each aquarium contains 25 fish. Fish were exposed to the chemicals for $96 \mathrm{~h}$ (96-h acute bioassay).

\section{Biochemical and endocrine analyses}

After exposure of fish to agrochemicals for $96 \mathrm{~h}$ fish from each aquarium were collected and anesthetized with clove oil Blood samples were collected from the caudal vein of fish by using sterile syringes and immediately transmitted to a tube, allowed to clot. Collected blood samples were spun at $3000 \mathrm{rpm}$ for $5 \mathrm{~min}$ to obtain blood serum. Sera were used for determination of biochemical parameters i.e., serum protein, serum glucose, triglyceride, cholesterol, creatinine, serum amylase, serum lipase and alkaline phosphatase, $\mathrm{Na}, \mathrm{P}, \mathrm{Mg}$ and endocrine parameters i.e., thyroid stimulating hormone (TSH), triiodothyronine (T3), tetraiodothyronine (T4), cortisol and insulin. Fully automated biochemical analyzer COBAS e 411 of Roche with ElectroChemi-luminescence technology \& CE approved $4^{\text {th }}$ generation immunodiagnostic kits was used for the analyses.

\section{Genotoxicity (Micronucleus assay)}

For MN assay blood samples were taken from the caudal fin of fish by using disposable heparinized syringes and then transferred into EDTA tubes after that two drops of blood were applied immediately on clean grease free slides for making peripheral blood smears, two for each fish specimen. These slides were air dried for $24 \mathrm{~h}$ and then dipped into cold absolute methanol for $15 \mathrm{~min}$ and then air dried for one hour. Slides were stained with Giemsa dye in phosphate buffer for $30 \mathrm{~min}$ then slides were washed and dried. Prepared slides were observed under 100x oil emersion lens. Then total magnification becomes $10 \times 100$ $=1000$ ) and frequency for MN were counted by using following formula:

$$
\mathrm{MN} \%=\frac{\text { Number of cells containing MN }}{\text { Total number of cells counted }} \times 100
$$

\section{Statistical analysis}

The data for biochemical parameters, endocrine parameters and micronuclei frequency was statistically analyzed using SPSS $^{\circledR}$ statistics software (version 24.0. Intergroup comparison was made by using one-way ANOVA while ttest was used for comparison between control and experimental group. The critical significance was set at 0.05 .

\section{Results}

\section{Physico-chemical parameters of water}

The physico-chemical properties of laboratory water and experimental condition were regularly examined during the experiment. The reported values were as Mean \pm SD for different parameters and are shown in Table 1. 
Table 1: Physico-chemical parameters of laboratory water

\begin{tabular}{llll}
\hline Parameters & Data & Parameters & Data \\
\hline Temperature & $21 \pm 1.19^{\circ} \mathrm{C}$ & Calcium hardness & $44 \pm 1.55 \mathrm{mg} / \mathrm{L}$ \\
PH & $7.5 \pm 0.23$ & Total alkalinity & $129 \pm 4.89 \mathrm{mg} / \mathrm{L}$ \\
Dissolve oxygen & $6.4 \pm 0.53$ & Conductivity & $819 \pm 14.9 \mathrm{~ms} / \mathrm{L}$ \\
Total dissolved solids & $366 \pm 10.81 \mathrm{mg} / \mathrm{L}$ & Chloride & $18.5 \pm 2.1 \mathrm{mg} / \mathrm{L}$ \\
\hline
\end{tabular}
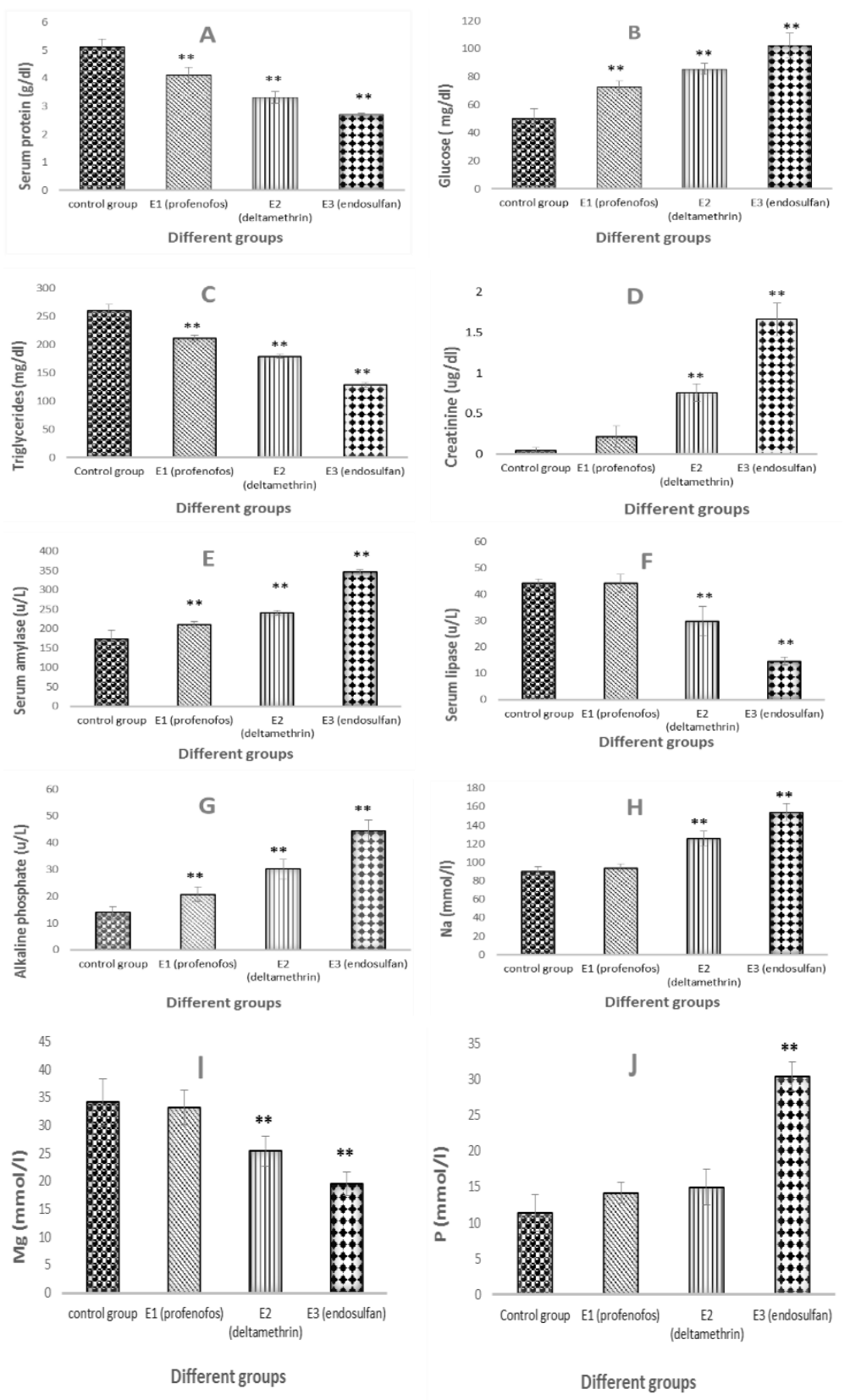

Fig. 1: A-J Serum protein, glucose, triglycerides, creatinine, serum amylase, serum lipase, ALP, Na, Mg and P levels of $C$. carpio after 96$\mathrm{h}$ exposure to profenofos, deltamethrin and endosulfan. Sign $\left(^{* *}\right)$ indicates significant difference $(P<0.05)$ to each other

\section{Behavioral changes in C. carpio}

Several changes in the behavior of treated group of $C$. carpio were observed throughout the experiment which varies from mild to severe depending upon the toxicity of pesticide. Various behavioral abnormalities shown by fish were, loss of body equilibrium, sinking to bottom, swimming at lateral side, darting swimming movement, 
Table 2: MNi frequency in control and treated groups of C. carpio

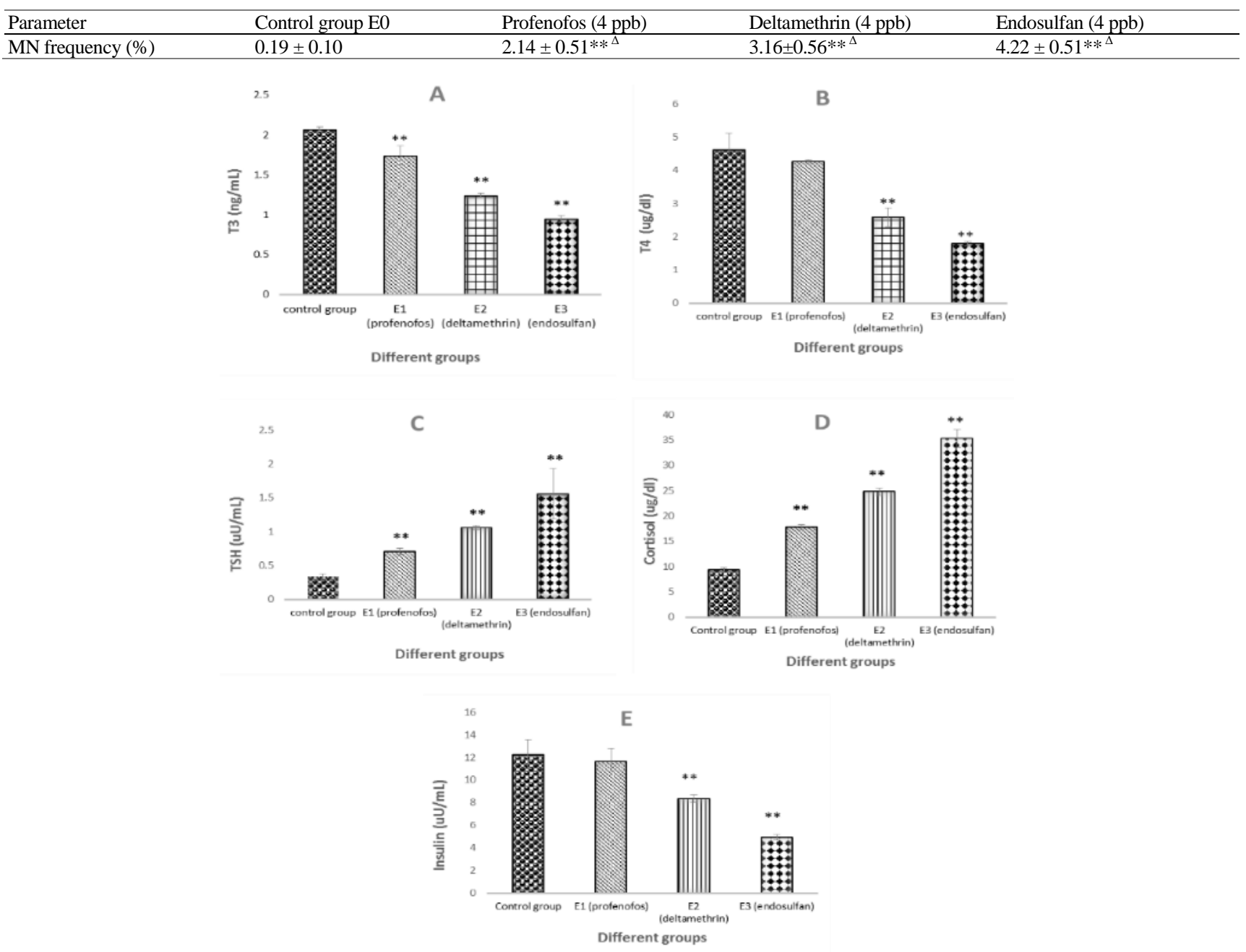

Fig. 2: (A-E) T3, T4, TSH, cortisol and insulin level of $C$. carpio against profenofos, deltamethrin and endosulfan exposure. Sign (**) indicates significant difference $(P<0.05)$ to each other

hyper-excitability, increase in movement of operculum, mucus secretions and due to stress some fishes tried to jump out of aquarium on the other hand no such type of alterations were noticed in control group of fish.

\section{Biochemical analyses}

In the present study $C$. carpio exposed to profenofos, deltamethrin and endosulfan showed alterations in biochemical parameters in response to agrochemical exposure as presented in Fig. 1 A-J. The values of serum protein and triglycerides decreased significantly in all treatment groups, while values of serum lipase and magnesium insignificantly decreased in group E1 exposed to profenofos, while significantly decreased in group E2 and E3 exposed to deltamethrin and endosulfan respectively. The values of glucose, serum amylase and alkaline phosphatase increased significantly in all the treated groups while $\mathrm{Na}$ and creatinine increased slightly in treated group I and significantly in group II and III, P level increased slightly in treated group I and II while significantly in group III compared to control group. The order of toxicities was endosulfan $>$ deltamethrin $>$ profenofos.

\section{Endocrine parameters}

In the present study endocrine variations in C. carpio was assessed on exposure to Profenofos, Deltamethrin and Endosulfan for 96-h as presented in Fig. 2 A-E. Values of T3 decreased significantly $(P<0.05)$ in all the treated groups while $\mathrm{T} 4$ decreased slightly in group I exposed to profenofos while significantly in group II and III exposed to deltamethrin and endosulfan respectively. TSH and cortisol values increased significantly $(P<0.05)$ in all the treated groups while values of insulin decrease slightly in group I and significantly in group II and III. No such type of 
alteration was recorded in endocrine parameters of fish belonging to control group. The order of toxicity of agrochemical was Endosulfan > Deltamethrin > Profenofos.

\section{Estimation of genotoxic effect through MN assay}

After agrochemical exposure micronuclei induction was observed in all the treated groups as compared to control group (Fig. 3). The highest micronuclei frequency was recorded against treated group III $(4.22 \%)$ exposed to endosulfan while lowest $\mathrm{MN}$ frequency was calculated against group I (2.14\%) exposed to profenofos (Fig. 4), which shows that endosulfan is more toxic amongst all three selected agrochemicals. The Micronuclei frequency increased in order of Endosulfan > Deltamethrin> Profenofos as represented in Table 2.

\section{Discussion}

Current study was conducted to assess the biochemical, endocrine and genotoxic effect of selected agrochemicals on C. carpio as an experimental model. To our knowledge, the present study provides the first ecotoxicological assessment for selected agrochemicals by using a multi-biomarker approach in a C. carpio. Our results indicated that a low acute sublethal exposure to agrochemicals in C. carpio has significant effects on the fish physiology and behavior. During experiment fish in E0, control group, showed normal behavior while various behavioral abnormalities were shown by treated group of fish such as; loss of body equilibrium, sinking to bottom, swimming at lateral side, darting swimming movement, hyper-excitability, increase in movement of operculum, mucus secretions and due to stress some fishes tried to jump out of aquarium. Similar changes were noticed by (Ghelichpour et al. 2020) by exposing $C$. carpio to lufenuron and by (Ghayyur et al. 2020) in $C$. mrigala against chlorfenapyr, dimethoate and acetamiprid exposure.

Biochemical study plays a vital role in monitoring fish health and assessing toxic effect of pollutants on aquatic organism (Poopal et al. 2017). The findings of present study showed a significant decrease in serum protein and triglycerides of agrochemical exposed fish as compare to control group. This result was in agreement with that of (Khan et al. 2019) in C. carpio treated with endosulfan and $O$. orientalis exposed to Cypermethrin (Shruti and Tantarpale 2014). The hypoproteinemia in present investigation might be due to boosted proteolysis, proteolysis seems to offer a physiological mechanism in a bid to provide energy to deal with stressful condition created by toxicant exposure. Triglyceride are major energy reserve in fish, the decline in triglyceride level in present investigation represent liver dysfunction (Prakash and Verma 2020). Similar results were obtained by (Qadir et al. 2014) when they exposed $L$. rohita to imidacloprid. Glucose is the major source of energy and its higher level in plasma

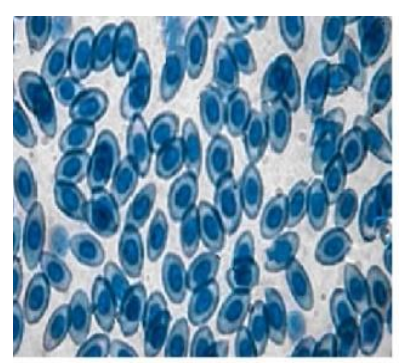

(A)

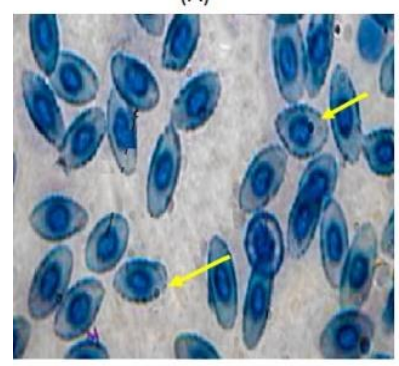

(C)

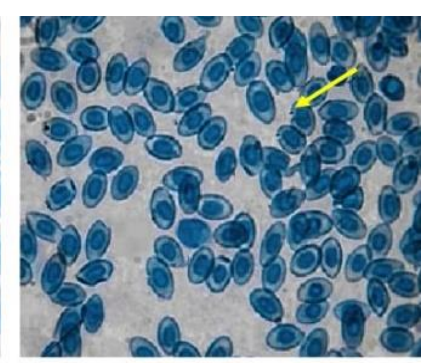

(B)

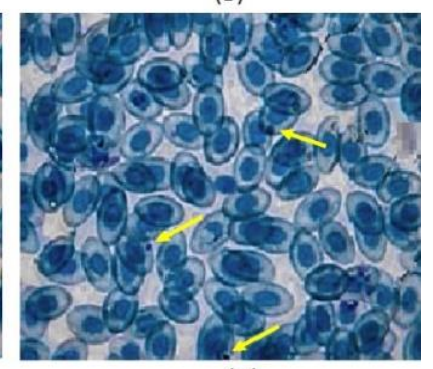

(D)
Fig. 3: $\mathrm{MNi}$ induction in erythrocytes of control, E0, (A) profenofos $(\mathbf{B})$, deltamethrin $(\mathbf{C})$ and endosulfan $(\mathbf{D})$ treated groups

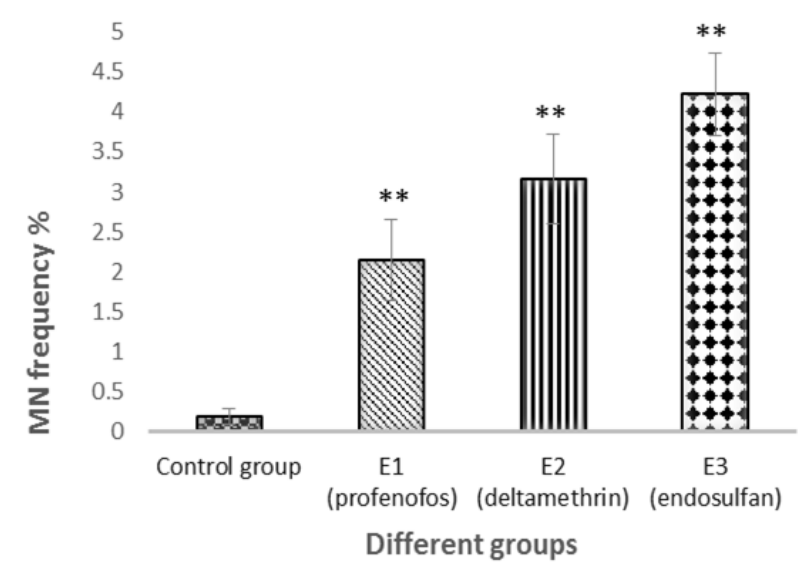

Fig. 4: Frequency (\%) of MNi in erythroctes of $C$. carpio against Profenofos, Deltamethrin and Endosulfan exposure. Sign $(* *)$ indicates significant difference $(P<0.05)$ to each other

act as a stress indicator in present study significant increase in glucose level observed. Our results was in line with findings of (Khan et al. 2018) and (Ghayyur et al. 2019). Changes in creatinine level shows kidney dysfunction, in present study level of creatinine increased in fish exposed to agrochemical in comparison to control group which may be due to oxidative damage. Similar consequences were reported by (Prusty et al. 2011). Our result also show similarity with the findings of (Amin and Hashem 2012) they noticed an increase in creatinine level in $C$. gariepinus against deltamethrin exposure.

When toxicants enter different tissues are injured and damaged cells release specific enzymes, in this investigation treated fish revealed elevation in alkaline phosphatase. 
Increase in ALP might be due to destruction of cell membrane of liver cells (Rahman et al. 2019). Similar increase in ALP was recorded by (Rahman et al. 2020) in $C$. carpio, by (Ghayyur et al. 2020) in Cirrhinus mrigala and by (Sancho et al. 2017) in Anguilla anguilla. Alteration in serum amylase indicates abnormality of digestive process in present study serum amylase increased in treated groups of fish, similar trend have been reported by (Lundstedt et al. 2004) and (Khan et al. 2019). Declined level of lipase due to agrochemical exposure may also be justified by the increased protein catabolism and reduced protein anabolism due to stress or may be due to decreased lipid levels. Similar reduction was reported in C. carpio exposed to malathion, chlorpyrifos and dimethoate (Rani et al. 2017).

Blood electrolytes are bio-indicator of physiology and health Status of fish. In present investigation values of sodium and phosphorus increased while magnesium level decreased. Increase in sodium and phosphorus was also reported by (Borges et al. 2007) when fish was exposed to Cypermethrin. Similar to our findings increase in sodium was reported by (Akhtar et al. 2019) in Schizothorax esocinus exposed to Cypermethrin. Our result shows disagreement with findings of (Atamanalp et al. 2002) who reported decrease in phosphorus after exposure of fish to cypermethrin.

Many fishes respond to stressors by showing endocrine shifts. In present study $C$. carpio showed decline in plasma T3 and T4 while significant increase in plasma TSH level. This result was in agreement with that reported by (Thangavel et al. 2010) in S. mossambicus exposed to endosulfan and by (Ghayyur et al. 2020) in Cirrhinus mrigala. Reduction in plasma T3 occur possibly because of diminution of $\mathrm{T} 4$ secretion or production (Li et al. 2008). Cortisol is an adrenocortical hormone involves in ion regulation and energy metabolism and used as a primary indicator of stress; it showed a significant increase in present study. Our results are in line with findings of other researchers e.g. C. carpio exposed to trichlorfon (Woo and Chung 2020), C. carpio exposed to cyfluthrin (SepiciDinçel et al. 2009) and Salmo salar exposed to atrazine (Waring and Moore 2004). In present study decline in level of insulin was recorded, the toxicant may have injured the islets of Langerhans which reduce the insulin secretion from $\beta$-cells (Thoker 2015). Similar to our outcomes, decline in insulin level was reported in Danio rerio (Ahmad et al. 2018), due to inhibition of $\beta$-cells by toxicant. Our result shows dissimilarity with the findings of (Shah et al. 2019) in which they reported an increase in insulin level of fish against dimethoate exposure.

MN assay is mostly used to detect biological impacts of aquatic pollutants on aquatic organisms, micronuclei induction in peripheral erythrocytes is due to genotoxic effect of pollutants (Tripathy 2020). Present study revealed genotoxicity of agrochemical in the peripheral erythrocytes of $C$. carpio as indicated by $\mathrm{MN}$ assay. Genetic damage increased in treated groups of fish as compare to control group, represented by formation of $\mathrm{MN}$ in erythrocytes. Our results show agreement with the findings of (Naqvi et al. 2016) when they treated $O$. mossambicus with different pesticides and (D'Costa et al. 2018) in Danio rerio exposed to monocrotophos. Similar genotoxic effects were also reported in erythrocytes of Grass carp on exposure to chromium, lead and copper (Shah et al. 2020). Likewise thiamethoxam administration also result in significant increase in micronuclei frequency in L. rohita (Ghaffar et al. 2020). Similar increase in micronucleus frequency was also reported in $O$. mykiss treated with fipronil (Ucar et al. 2020).

\section{Conclusion}

Present investigation clearly confirmed the harmful impacts of selected agrochemicals on biochemical, endocrine and genetic profile of $C$. carpio which showed that genetic, biochemical and endocrine parameters can be used as efficient biomarker for ecotoxicology. On the basis of current investigation, we can conclude that agrochemical pose serious threat to aquatic life in order to minimize poisonous effects of agrochemicals its use should be minimized and environment friendly agrochemical should be formulated having fast degrading ability and more target specificity.

\section{Acknowledgments}

This study was supported by the Higher Education Commission of Pakistan (10108).

\section{Author Contributions}

Sanaa: Perform experiment, Shehzad Ghayyur: Designed the study, Sadia Tabassum \& Shumaila Noreen: Review the article, Sajid Mahmood: Analyzed the data, Mujadad Ur Rehman \& Bashir Ahmad: Help in sample collection, Muhammad Kabir \& Muhammad Sajid: Write the article, Muhammad Fiaz Khan: Supervised the study

\section{Conflict of Interest}

The auther have no conflict of interest.

\section{Data Availability}

Data presented in this study are available on fair request to the corresponding author.

\section{Ethics Approval}

All the experimental work was conducted in accordance with the ethical guideline approved by the ethical committee of Hazara University, Mansehra, Pakistan. 


\section{References}

Ahmad S, V Yadav, K Zahra (2018). A study on the effects of Chlorpyrifos $20 \%$ EC with particular emphasis on endocrinal secretions in zebra fish, Danio rerio. Intl J Basic Appl Res 8:203-213

Akhtar N, M khan, S Tabassum (2019). Sub lethal effects of atrazine on hematology, histopathology and biochemistry of chirruh snowtrout (Schizothorax esocinus). J Anim Plant Sci 29:1447-1454

Al-Otaibi A, H Al-Balawi, Z Ahmad, E Suliman (2019). Toxicity bioassay and sub-lethal effects of diazinon on blood profile and histology of liver, gills and kidney of catfish, Clarias gariepinus. Braz J Biol 79:326-336

Amin KA, KS Hashem (2012). Deltamethrin-induced oxidative stress and biochemical changes in tissues and blood of catfish (Clarias gariepinus): antioxidant defense and role of alpha-tocopherol. $B M C$ Vet Res 8; Article 45

Atamanalp M, KM Salt, HI Haliloglu, MS Aras (2002). The effects of cypermethrin (a synthetic pyrethroid) on some biochemical parameters $(\mathrm{Ca}, \mathrm{P}, \mathrm{Na}$ and $\mathrm{TP})$ of rainbow trout (Oncorhynchus mykiss). Turk J Vet Anim Sci 26:1157-1160

Borges A, LV Scotti, DR Siqueira, R Zanini, FDO AmaraL, DF Jurinitz, GF Wassermann (2007). Changes in hematological and serum biochemical values in jundiá Rhamdia quelen due to sub-lethal toxicity of cypermethrin. Chemosphere 69:920-926

Bradberry SM, SA Cage, AT Proudfoot, JA Vale (2005). Toxicological Reviews Copyright 2005 Adis Data Information BV. In: Poisoning Due to Pyrethroids, Vol. 2, pp:93-106

Caliani I, LP Rodríguez, S Casini, A Granata, G Zagami, M Pansera, G Querci, R Minutoli (2019). Biochemical and genotoxic biomarkers in Atherina boyeri to evaluate the status of aquatic ecosystems. Region Stud Mar Sci 28:100566

Costa LG (2015). The neurotoxicity of organochlorine and pyrethroid pesticides.In: Handbook Clinical Neurology. Elsevier, The Netherlands

D'Costa HA, S Shyama, MP Kumar, TM Fernandes (2018). Induction of DNA damage in the peripheral blood of zebrafish (Danio rerio) by an agricultural organophosphate pesticide, monocrotophos. Intl Aquat Res 10:243-251

Finney DJ (1980). Probit Analysis, $3^{\text {rd }}$ edn. Cambridge Univ Press, UK

Ghaffar A, R Hussain, S Noreen, G Abbas, IR Chodhary, A Khan, Z Ahmed, MK Khan, K Akram, M Ulhaq (2020). Dose and timerelated pathological and genotoxic studies on thiamethoxam in fresh water fish (Labeo rohita) in Pakistan. Pak Vet J 40:151-156

Ghayyur S, MF Khan, S Tabassum, MS Ahmad, M Sajid, K Badshah, MA Khan, S Ghayyur, NA Khan, B Ahmad (2020). A comparative study on the effects of selected pesticides on hemato-biochemistry and tissue histology of freshwater fish Cirrhinus mrigala (Hamilton 1822). Saud J Biol Sci 28:603-611

Ghayyur S, S Tabassum, MS Ahmad, N Akhtar, MF Khan (2019). Effect of chlorpyrifos on hematological and seral biochemical components of fish Oreochromis mossambicus. Pak J Zool 51:1047-1052

Ghelichpour M, AT Mirghaed, SM Hoseini, AP Jimenez, A (2020). Plasma antioxidant and hepatic enzymes activity, thyroid hormones alterations and health status of liver tissue in common carp (Cyprinus carpio) exposed to lufenuron. Aquaculture 516:734634

Guo Y, XZ Meng, HL Tang, EY Zeng (2008). Tissue distribution of organochlorine pesticides in fish collected from the Pearl River Delta, China: implications for fishery input source and bioaccumulation. Environ Pollut 155:150-156

Gupta S, A Pal, N Sahu, A Jha, M Akhtar, S Mandal, P Das, A Prusty (2013). Supplementation of microbial levan in the diet of Cyprinus carpio fry (Linnaeus 1758) exposed to sublethal toxicity of fipronil: effect on growth and metabolic responses. Fish Physiol Biochem 6:1513-1524

Hemalatha D, B Nataraj, B Rangasamy, K Maharajan, M Ramesh (2020). Exploring the sublethal genotoxic effects of class II organophosphorus insecticide quinalphos on freshwater fish Cyprinus carpio. J Oceanol Limnol87:1-10
Hussain R, A Ghaffar, G Abbas, G Jabeen, I Khan, RZ Abbas, S Noreen, Z Iqbal, IR Chaudhary, HM Ishaq (2020). Thiamethoxam at sublethal concentrations induces histopathological, serum biochemical alterations and DNA damage in fish (Labeo rohita). Toxin Rev 40: In Press

Isaac AO, OS Joshua, A Jehu (2017). Behavioural and some physiological assessment of glyphosate and paraquat toxicity to juveniles of african catfish, Clarias gariepinus. Pak J Zool 49:183-190

Khan MF, S Tabassum, H Sadique, M Sajid, S Ghayyur, S DIL, NK Badshah, I Ullah (2019). Hematological, biochemical and histopathological alterations in common carp during acute toxicity of endosulfan. Intl J Agric Biol 22:703-709

Khan N, S Tabassum, M Ahmad, F Norouz, A Ahmad, S Ghayyur, AU Rehman, MF Khan (2018). Effects of sub-lethal concentration of cypermethrin on histopathological and hematological profile of rohu (Labeo rohita) during acute toxicity. Intl J Agric Biol 20:601-608

Li D, P Xie, X Zhang (2008). Changes in plasma thyroid hormones and cortisol levels in crucian carp (Carassius auratus) exposed to the extracted microcystins. Chemosphere 74:13-18

Lundstedt L, JFB Melo, G Moraes (2004). Digestive enzymes and metabolic profile of Pseudoplatystoma corruscans (Teleostei: Siluriformes) in response to diet composition. Compar Biochem Physiol Part B Biochem Mol Biol 137:331-339

NaqvI GEZ, N Shoaib, AM Ali (2016). Genotoxic potential of pesticides in the peripheral blood erythrocytes of fish (Oreochromis mossambicus). Pak J Zool 48:1643-1648

Poopal R, M Ramesh, V Maruthappan, R Baburajendran (2017). Potential effects of low molecular weight phthalate esters $\left(\mathrm{C}_{16} \mathrm{H}_{22} \mathrm{O}_{4}\right.$ and $\left.\mathrm{C}_{12} \mathrm{H}_{14} \mathrm{O}_{4}\right)$ on the freshwater fish Cyprinus carpio. Toxicol Res 6:505-520

Prakash S, AK Verma (2020). Effect of Arsenic on Serum Biochemical parameters of a fresh water cat fish, Mystus vittatus. Intl J Biol Innovat 2:11-19

Prusty A, M Kohli, N Sahu, A Pal, N Saharan, S Mohapatra, S Gupta (2011). Effect of short term exposure of fenvalerate on biochemical and haematological responses in Labeo rohita (Hamilton) fingerlings. Pest Biochem Physiol 100:124-129

Qadir S, A Latif, M Ali, F Iqbal (2014). Effects of imidacloprid on the hematological and serum biochemical profile of Labeo rohita. Pak J Zool 46:1085-1090

Rahman ANA, AAR Mohamed, HH Mohammed, NM Elseddawy, GA Salem, WR El-ghareeb (2020). The ameliorative role of geranium (Pelargonium graveolens) essential oil against hepato-renal toxicity, immunosuppression, and oxidative stress of profenofos in common carp, Cyprinus carpio (L.). Aquaculture 517; Article 734777

Rahman ANA, M Elhady, ME Hassanin, AAR Mohamed (2019). Alleviative effects of dietary Indian lotus leaves on heavy metalsinduced hepato-renal toxicity, oxidative stress, and histopathological alterations in Nile tilapia, Oreochromis niloticus (L.). Aquaculture 509:198-208

Rahman MM (2015). Effects of co-cultured common carp on nutrients and food web dynamics in rohu aquaculture ponds. Aquacult Environ Interact 6:223-232

Rani M, J Yadav, S Kumar, RK Gupta (2017). Impact of organophosphates on blood serum enzymes of Indian major carps. J Entomol Zool Stud 5:1865-1868

Reddy NC, JV Rao (2008). Biological response of earthworm, Eisenia foetida (Savigny) to an organophosphorous pesticide, profenofos. Ecotoxicol Environ Saf 71:574-582

Sancho E, O Andreau, MJ Villarroel, C Fernández-vega, F Tecles, S Martínez-subiela, JJ Cerón, MD Ferrando (2017). European eel (Anguilla anguilla) plasma biochemistry alerts about propanil stress. J Pest Sci 16-062

Sathyamoorthi A, V Kumaresan, R Palanisamy, M Pasupuleti, MV Arasu, NA Al-Dhabi, K Marimuthu, SN Amin, A Arshad, FM Yusoff (2019). Therapeutic cationic antimicrobial peptide (CAP) derived from fish aspartic proteinase Cathepsin D and its antimicrobial mechanism. Intl J Pept Res Therapeut 25:93-105 
Sepici-dinçel A, ACK Benli, M Selvi, R Sarıkaya, D Şahin, IA Özkul, F Erkoç (2009). Sublethal cyfluthrin toxicity to carp (Cyprinus carpio L.) fingerlings: biochemical, hematological, histopathological alterations. Ecotoxicol Environ Saf 72:1433-1439

Shah N, A Khan, NH Khan, M Khisroon (2020). Genotoxic consequences in common grass carp (Ctenopharyngodon idella valenciennes, 1844) exposed to selected toxic metals. Biol Trace Elem Res 199:305-314

Shah ZU, S Parveen, BN Bhat (2019). Hormonal response of freshwater fish Cyprinus carpio (Linnaeus) to dimethoate exposure. World 8:1-7

Shruti SG, V Tantarpale (2014). Protein and amino acid modulation in fresh water fish Ophiocephalus orientalis exposed to cypermethrin. $J$ Pharm Sci Innovat 3:344-347

Talapatra S, S Banerjee (2007). Detection of micronucleus and abnormal nucleus in erythrocytes from the gill and kidney of Labeo bata cultivated in sewage-fed fish farms. Food Chem Toxicol 45:210-215

Thangavel P, K SumathiraL, S Maheswari, S Rita, M Ramaswamy (2010). Hormone profile of an edible, freshwater teleost, Sarotherodon mossambicus (Peters) under endosulfan toxicity. Pest Biochem Physiol 97:229-234

Thoker MA (2015). Comparative study of biochemical alterations induced by carbofuran and malathion on Channa punctatus (Bloch.). Intl Res J Biol Sci 4:61-65
Tripathy SK (2020). An anthology of cytogenetic end points like micronucleus test, commet assay and chromosomal aberration assay in pisces. Intl J Agric Nat Sci 13:126-150

Ucar A, V Parlak, AÇ Yeltekin, FB Özgeris, O Caglar, H Turkez, G Alak, M Atamanalp (2020). Assesment of hematotoxic, oxidative and genotoxic damage potentials of fipronil in rainbow trout Oncorhynchus mykiss, Walbaum. Toxicol Mech Meth 31:73-80

Waring CP, A Moore (2004). The effect of atrazine on Atlantic salmon (Salmo salar) smolts in fresh water and after sea water transfer. Aquat Toxicol 66:93-104

Woo SJ, JK Chung (2020). Effects of trichlorfon on oxidative stress, neurotoxicity, and cortisol levels in common carp, Cyprinus carpio L., at different temperatures. Compar Biochem Physiol Part C Toxicol Pharmacol 229:108698

Xiao X, JM Clark, Y Park (2017). Potential contribution of insecticide exposure and development of obesity and type 2 diabetes. Food Chem Toxicol 105:456-474

Zhang H, X Hong, S Yan, J Zha, J Qin (2020). Environmentally relevant concentrations of bifenthrin induce changes in behaviour, biomarkers, histological characteristics, and the transcriptome in Corbicula fluminea. Sci Total Environ 728; Article 138821 